\title{
Combined effects of irradiation and storage time on the nutritional and chemical parameters of dried Agaricus bisporus Portobello mushroom flour
}

\author{
Rossana V. C. Cardoso ${ }^{1,2} \quad \mid \quad$ Marcio Carocho $^{1}$ (D) | Ângela Fernandes ${ }^{1} \quad$ | \\ João C. M. Barreira ${ }^{1} \quad$ Sandra Cabo Verde ${ }^{3} \quad$ | Pedro M. P. Santos ${ }^{3}$ | \\ Amilcar L. Antonio ${ }^{1} \quad$ Ana M. Gonzaléz-Paramás ${ }^{2} \quad$ Lillian Barros ${ }^{1}$ | \\ Isabel C. F. R. Ferreira ${ }^{1}$ \\ ${ }^{1}$ Centro de Investigação de Montanha (CIMO), Instituto Politécnico de Bragança, Campus de Santa Apolónia, Bragança, Portugal \\ ${ }^{2}$ Grupo de Investigación en Polifenoles (GIP), Unidad de Nutrición y Bromatología, Facultad de Farmacia, Universidad de Salamanca, Campus \\ Miguel de Unamuno, Salamanca, Spain \\ ${ }^{3}$ Centro de Ciências e Tecnologias Nucleares, Instituto Superior Técnico, Universidade de Lisboa, Bobadela, Portugal
}

\author{
Correspondence \\ Marcio Carocho and Lillian Barros, Centro \\ de Investigação de Montanha (CIMO), \\ Instituto Politécnico de Bragança, Campus \\ de Santa Apolónia, 5300-253 Bragança, \\ Portugal. \\ Email: mcarocho@ipb.pt and \\ lillian@ipb.pt \\ Funding information \\ Fundação para a Ciência e a Tec- \\ nologia, Grant/Award Num- \\ bers: CEECIND/00831/2018, \\ SFRH/BD/137436/2018, \\ UID/Multi/04349/2013, \\ UIDB/AGR/00690/2020; European Agri- \\ cultural Fund for Rural Development, \\ Grant/Award Number: PDR2020-101- \\ 031472
}

\begin{abstract}
Portobello variety of Agaricus bisporus mushrooms, appreciated for its taste, makes it desirable to be eaten fresh and also as flour in soups and gravies. Gamma and electron-beam radiation at four doses (1, 2, 5, and $10 \mathrm{kGy})$ were used to analyze its preservation effect on Portobello mushroom flour. A proximate analysis, as well as the impact on fatty acids, tocopherols, soluble sugars, organic acids, and ergosterol profiles, were performed every 3 months, during a storage period of 1 year. Gamma rays preserved mannitol (most abundant soluble sugar) over the 12 months, while electron beam radiation preserved organic acids. No significant changes were sought for any radiation type, and the slight changes extracted from the estimated marginal means reveal a tendency for irradiation as having preserving effects of nutrients and other important molecules. Thus, both irradiation types, up to $10 \mathrm{kGy}$ are suitable for preservation of $A$. bisporus Portobello flour.
\end{abstract}

KEYWORDS

Agaricus bisporus, chemical profile, electron beam, food irradiation, gamma radiation

\section{1 | INTRODUCTION}

As the consumption of fresh mushrooms grows, an increase in their production is necessary, demanding additional research to clarify the role of mushrooms in human diets and their consumption benefits (PR Newswire, 2018). In the post-harvest stage, mushrooms quickly lose quality, as indicated by the loss of moisture, discoloration, degra- dation of nutrients, and hyphae development. This high perishability is a strong disadvantage that reduces their economic value. Accordingly, there is a growing need to extend their shelf life, both in fresh and processed forms, improving yields and economic competitiveness to producers and traders, and increasing their quality for consumers (Bernaś, 2018; Cardoso et al., 2019; Kic, 2018; Taofiq et al., 2017; Zhang et al., 2018). 
Irradiation technology has proven to be scientifically feasible, practical, and worthwhile for several food products (fruits and vegetables, fresh or dried; Akram et al., 2013; Cardoso et al., 2019; Fernandes et al., 2017; Ferreira et al., 2018). Gamma rays and electron-beam radiation are techniques that have been validated previously and constitute an alternative to other preservation technologies (Ferreira et al., 2018) while maintaining the chemical profile, freshness, and overall security, although the beneficial and negative effects are always dose-dependent and case-specific; hence, the importance of testing doses within current legislation on different foods (Cardoso et al., 2019; Fernandes, Barreira, et al., 2014a, 2014b). Scientific reports have shown the benefits of this technology on the physical, chemical, nutritional and bioactive properties of several edible mushroom species mushrooms (Cardoso et al., 2019; Fernandes et al., 2013b, 2015, 2017; Fernandes, Barreira, et al., 2014a, 2014b, 2014c, Fernandes et al., 2016).

The Agaricus bisporus (J.E. Lange) Imbach, white mushrooms, are the ones within the Agaricaceae family with the least growth time in order to have the white and soft body, which when allowed to grow for longer periods, starts to develop a brown tone that tends to intensify. These brown mushrooms are called Portobello and have a more intense and textured taste than the white ones (Bernaś, 2018; Cardoso et al., 2019; Djekic et al., 2017; Wang et al., 2018). Additionally, this variety is rich in bioactive compounds (Cardoso et al., 2019; Djekic et al., 2017; Guan et al., 2016; Teichmann et al., 2007).

Interaction of ionizing radiation with natural matrices is multifactorial, where some molecules may protect others from radiation effects, requiring case-by-case studies (Antonio et al., 2018). In this way, validating both the processing technology and the processed product is a requisite to assure the feasibility of the preservation process under validation. Still, gamma and electron-beam irradiation does not induce deep changes in fresh or dried mushrooms (Cardoso et al., 2020). Accordingly, the main objective of this work was to understand the effects of different doses $(1,2,5$, and $10 \mathrm{kGy})$ of gamma and electron-beam irradiation on nutritional and chemical parameters of Portobello mushrooms flour stored for relatively long storage periods ( 0,6 , and 12 months).

\section{2 | MATERIALS AND METHODS}

\section{1 | Gamma and electron-beam irradiation}

A. bisporus Portobello fruiting bodies were acquired in a local market of Bragança, Northeast of Portugal in June
2017, and were divided into two groups of 15 mushrooms each and further submitted to a drying process. Samples were dried at $30^{\circ} \mathrm{C}$ in an oven for 4 days; each group was further subdivided into five subgroups (200 g per group): Control (non-irradiated, $0 \mathrm{kGy}$ ); sample 1, irradiated at $1 \mathrm{kGy}$, sample 2 ( $2 \mathrm{kGy}$ ), sample 3 (5 kGy) and sample 4 (10 kGy).

Gamma irradiation was performed at the ionizing radiation facility IRIS from Centro de Ciências e Tecnologias Nucleares (Instituto Superior Técnico, Universidade de Lisboa, Lisbon, Portugal) in a ${ }^{60} \mathrm{Co}$ experimental chamber (model Precisa 22, Graviner Manufacturing Company Ltd., UK) with four sources and a total activity of $2.9 \mathrm{kCi}(108$ TBq, July 2017). The absorbed doses were measured by routine dosimeters (Batch X; Amber Perspex Harwell). Prior to irradiation, two dosimeters were added to each bag, and the samples were placed in line with the sources, rotated 180 degrees vertically and horizontally halfway through the irradiation to guarantee a uniform dose and to follow the recommended practices for food irradiation (dose uniformity ratio less than 3 ). The dosimeters were positioned according to a previous dose mapping of the irradiation chamber, and the absorbed doses were estimated using a calibration curve obtained for routine dosimeters.

The estimated absorbed doses, dose rate, and dose uniformity ratio $\left(D_{\max } / D_{\min }\right)$ were, respectively, $1.2 \pm 0.1$, $1.9 \pm 0.1,5.0 \pm 0.1$, and $10.4 \pm 0.3 \mathrm{kGy} ; 1.4 \mathrm{kGy} / \mathrm{h}$ and 1.3 , respectively.

Electron-beam irradiation was carried out in the same facility using a LINAC equipment (Saturne 41, adapted for R\&D, General Electric Co., Boston, MA, USA) with an electron beam of $10 \mathrm{MeV}$. Samples were placed at $60 \mathrm{~cm}$ from the beam exit and irradiated at dose rates ranging from 0.3 to $1.3 \mathrm{kGy} / \mathrm{min}$ (pulse duration $4 \mu \mathrm{s}$, pulse repetition frequency $20-100 \mathrm{~Hz}$ ). The absorbed doses estimated by radiochromic film dosimeters FWT-60 (Far West Technology, Inc.) were the following: $1.0 \pm 0.1,2.0 \pm 0.2,4.7 \pm 0.7$, and $9.8 \pm 0.1 \mathrm{kGy}$ ) with an uncertainty of $7 \%$ for the first dose and $10 \%$ for the other two doses. Previously to food irradiation experiments, a detailed dose mapping characterization of the radiation chamber was carried out, $60 \mathrm{~cm}$ of the beam, using routine radiochromic dosimeters that were calibrated against reference alanine dosimeters.

After irradiation and prior to the laboratorial analysis, the samples were ground to a fine dried powder (20 mesh) by means of an automated mill and mixed to obtain homogenized samples, and then kept in the dark at room temperature in airtight flasks until further analysis. One batch of the samples was analyzed immediately while the other two were stored for 6 and 12 months, respectively, at room temperature in the dark in airtight containers. 


\section{2 | Proximate composition}

Carbohydrates, fat, protein, ash, and moisture were determined following AOAC (Association of Official Agricultural Chemists) procedures (AOAC, 2016). The crude protein content of the samples was determined by the macro-Kjeldahl method, the crude fat was extracted using a Soxhlet apparatus and subsequently weighed, the ash content was determined by incineration at $550 \pm 15^{\circ} \mathrm{C}$. Total carbohydrates were calculated by difference: Total carbohydrates $=100$ ( $\mathrm{g}$ of moisture $+\mathrm{g}$ of protein $+\mathrm{g}$ of fat $+\mathrm{g}$ of ashes); and energy was calculated according to the following equation: Energy $(\mathrm{kcal})=4 \times(\mathrm{g}$ protein $+\mathrm{g}$ carbohydrates $)+9 \times(\mathrm{g}$ fat $)$.

\section{3 | Chemical composition}

\subsection{1 | Soluble sugars}

For the analysis of soluble sugars, an extraction was performed with ethanol and water, followed by a filtration (Barros, Pereira, Calhelha, et al., 2013). The identification of soluble sugars was performed on a Knauer highperformance liquid chromatograph (HPLC; Smartline system 1000, Knauer, Berlin, Germany) coupled to a refractive index detector (RI; Knauer). The compounds were identified by comparing their retention times to the ones of commercial standards. The quantification was based on the RI signal response of each standard using the internal standard (IS) methodology and raffinose as the IS. The HPLC conditions were as following: The mobile phase was a mixture of acetonitrile/water $(70: 30, \mathrm{v} / \mathrm{v})$ with a flow rate of $1 \mathrm{ml} / \mathrm{min}$. The chromatographic separation was achieved using a Eurospher $100-5 \mathrm{NH}_{2}$ column $(5 \mu \mathrm{m}, 250 \times 4.6 \mathrm{~mm}$, Knauer) at $35^{\circ} \mathrm{C}$. Data were analyzed using Clarity 2.4 software (DataApex, Podohradska), and the results were reported in $\mathrm{g}$ per $100 \mathrm{~g}$ of dry weight (dw).

\subsection{2 | Organic acids}

Organic acids were extracted following a procedure previously described by the authors Pereira et al. (2015) and quantified by ultrafast liquid chromatograph (Shimadzu 20A series, Shimadzu Corp., Kyoto, Japan) coupled to photodiode array detector, using $215 \mathrm{~nm}$ as the preferred wavelength. Results were expressed as $\mathrm{g} / 100 \mathrm{~g}$ dw.

\subsection{3 | Fatty acids}

Fatty acids were determined by gas chromatography (GC) with flame ionization detection at $260^{\circ} \mathrm{C}$ after extrac- tion and derivatization procedures previously described by Heleno et al. (2009). The analysis was carried out with a DANI GC 1000 instrument (DANI Instruments, Milan, Italy) equipped with a split/splitless injector and a ZebronKame column $(30 \mathrm{~m} \times 0.25 \mathrm{~mm}$ ID $\times 0.20 \mu \mathrm{m}$ df, Phenomenex, Torrance, CA, USA) using the methodology previously reported by Cardoso et al. (2019). The results were expressed in the relative percentage of each fatty acid.

\subsection{4 | Tocopherols}

Tocopherols were quantified through HPLC after extraction with hexane, methanol, and water as previously described by Reis et al. (2012), using tocol as an IS. Chromatographic separation was performed with a polyamide II normal-phase column $(250 \times 4.6 \mathrm{~mm}$; YMC model, Waters Corp., Milford, MA, USA) operating at $35^{\circ} \mathrm{C}$, and the mobile phase employed was a mixture of $n$-hexane and ethyl acetate (70:30, v/v) at a flow rate of $1 \mathrm{~mL} / \mathrm{min}$. This analysis was done using the equipment described for the soluble sugars, although coupled to a fluorescence detector (FP-2020; Jasco), designed for excitation at $290 \mathrm{~nm}$ and emission at $330 \mathrm{~nm}$. Quantification was based on IS methodology, and the compounds were identified by chromatographic comparisons with commercial standards. Data were evaluated using Clarity 2.4 software, and the results were expressed in $\mathrm{mg} / 100 \mathrm{~g} \mathrm{dw}$.

\subsection{5 | Ergosterol}

Ergosterol was identified and quantified according to the methodology described by Barreira et al. (2014), after an extraction procedure previously described by Guan et al. (2016), using the HPLC described above coupled to a UV detector (Knauer Smartline 2500) and using $280 \mathrm{~nm}$ as the preferred wavelength (Barros et al., 2013a). The results were expressed as $\mathrm{mg} / 100 \mathrm{~g} \mathrm{dw}$.

\section{4 | Statistical analysis}

Throughout the manuscript, all assays were carried out with three replicates, and all data are expressed as mean \pm standard deviation. Samples were analyzed through a two-way analysis of variance (ANOVA) with type III sums of squares, after verifying homoscedasticity through a Levene's test. The post-hoc test used was either a Tukey's Honest Significant Difference (HSD) test (homoscedastic samples) or Tamhane's T2 test (non-homoscedastic samples). By employing a two-way ANOVA, it is possible to verify the 
influence of each factor: Storage time(ST) or radiation dose (RD), independently of the way the other factor varies. If a significant $(p<0.05)$ interaction $(\mathrm{ST} \times \mathrm{RD})$ was detected, the potential tendencies had to be extracted from the plotted estimated marginal means (EMM). Inversely, if there is no significant interaction ( $p>0.05$ ), each factor was classified independently using the post-hoc tests described above. All statistical analysis was performed using a $p$-value of 0.05 and the IBM SPSS software, version 25 (IBM Corp.).

\section{3 | RESULTS AND DISCUSSION}

The tabled results include nutritional, soluble sugars, and ergosterol profiles (Table 1), tocopherols and organic acids (Table 2), and fatty acids (Table 3) and are divided into two sections, the top one belonging to gamma-irradiated samples and the bottom one to those treated with the electron beam. Each section is further divided to elucidate ST (upper part) and RD (lower part) effects with the values presented for each RD including all ST periods and vice-versa.

In dw basis, the most abundant nutrients were carbohydrates, followed by proteins (Table 1). The fat content was

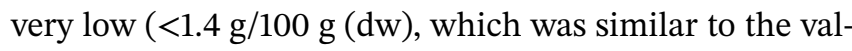
ues presented by other fresh mushroom species (Cardoso et al., 2019). For gamma-irradiated samples, there was a significant $(p<0.05)$ interaction $(\mathrm{ST} \times \mathrm{RD})$ for moisture, crude fat, proteins, and carbohydrates, meaning that both $\mathrm{RD}$ and ST had a significant impact on the changes registered for these nutrients. Inversely, ash and energy did not show a significant interaction, being classified individually. Ash content decreased over ST, although the significantly higher values in irradiated samples, as previously observed in irradiated foods (Khan et al., 2018). Regarding the energy values of gamma-irradiated samples, this parameter tended to increase with ST but decreased for higher RD. Considering the EMM plots, it was possible to observe that the longer the ST, the lower the fat content (Figure 1(a)), but with RDs of 5 and $10 \mathrm{kGy}$, this nutrient seems to be preserved, which is a beneficial aspect, since the loss of fat content is related to rancidification of food. Similar results were reported by Fernandes et al. (2017). Storage had a role in the reduction of fat over time, but the treatment at $5 \mathrm{kGy}$ seems to preserve the integrity of these molecules during storage.

In terms of the nutritional profile of electron-beamirradiated samples, a significant interaction was also found for ash and energy, showing that electron-beam had similar effects to those of gamma radiation, with a significant decrease of ash and an increase of energy values over ST, while a reduction of these parameters was detected with the increase of RD. For nutrients with a significant interaction among factors, the EMM plots (Figure 1(b)), show a reduction of protein content for the stored samples, while a lower dose of irradiation ( $1 \mathrm{kGy}$ ) seems to slightly reduce this loss of protein content in stored samples. This behavior was also reported by (Fernandes et al., 2013a; Fernandes, Barreira, et al., 2014b).

In Table 1, the soluble sugars and ergosterol content are shown for both irradiation technologies. The detected sugars were fructose, mannitol, and trehalose, mannitol being the most abundant one, followed by trehalose. The same sugar profile had been identified previously in various instances for irradiated sugars Regarding gamma radiation, a non-significant interaction was found for mannitol and trehalose while mannitol was classified independently showing that while this sugar decreased over ST, the increase of RD preserved it. Trehalose did not show significant differences among ST or RD, but it can be observed that trehalose increased over the 12 months with no influence from RD. The EMM plot for total sugars, Figure 1(c), shows that the amount of these sugars reduces over time, although stored samples showed that gamma irradiation had increasing preserving capacity from 1 to $5 \mathrm{kGy}$, while the $10 \mathrm{kGy}$ dose showed a better preserving potential in non-stored samples. Electron-beam-irradiated samples showed a significant interaction for all sugars with no observable tendency in the EMM.

Ergosterol was detected in samples irradiated by both technologies and showed a significant interaction with values around $239 \mathrm{mg} / 100 \mathrm{~g}$ for gamma irradiation and varying from 234 to $347 \mathrm{mg} / 100 \mathrm{~g}$ for electron beam. In a previous work by Cardoso et al. (2019), an increase in ergosterol was also recorded for irradiated samples. Overall, slight changes were detected in the nutritional and sugar profile of Portobello mushroom flour treated with gamma radiation or electron beam, clearly showing that ST had a higher impact than RD as can be observed in Figure 1.

Table 2 shows two classes of molecules detected in the mushrooms, namely, tocopherols and organic acids. Regarding tocopherols, all four isoforms were detected in gamma and electron-beam-irradiated mushrooms, with $\beta$-tocopherol showing the highest amounts and $\alpha$-tocopherol the lowest. A significative interaction was found for all isoforms, not allowing to present individual classifications. Considering the EMM plots, and starting by gamma radiation, a general tendency for preservation of tocopherols was found for doses of 1 kGy with a much deeper impact resulting from ST, which tended to reduce the amount of these bioactive molecules, (Figure 2(a)). This same tendency, a decrease in the bioactive molecules over time, had also been reported previously by Fernandes et al. (2017). In the case of electron-beam-irradiated mushroom flour, ST also 


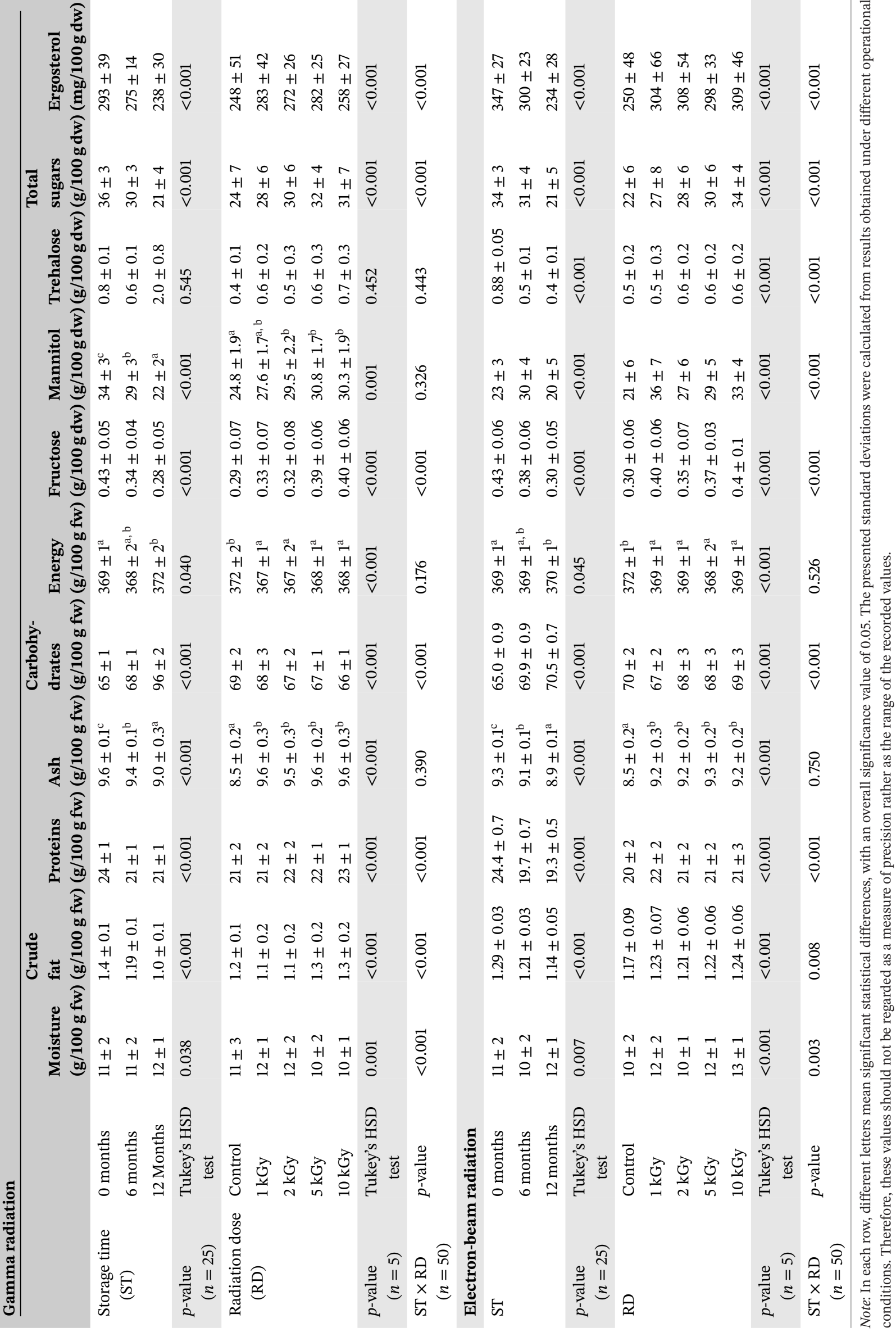


(3)

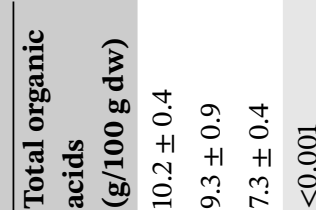

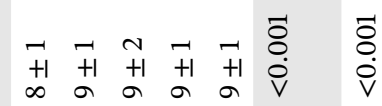

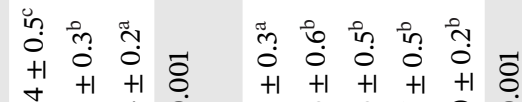

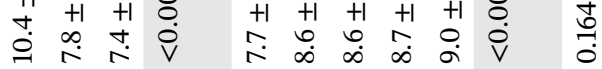

굴

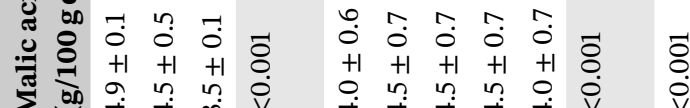

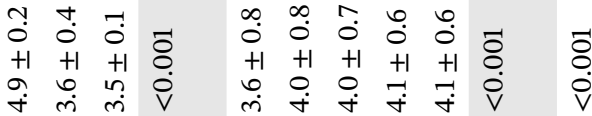

-

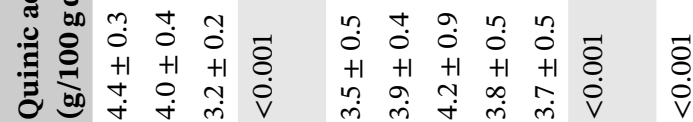

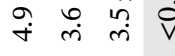

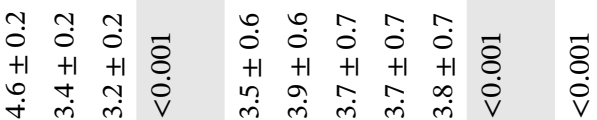

$\begin{array}{lll}+ & 8 & 8 \\ 0 & 0 & 0 \\ 0 & 0 & 0\end{array}$

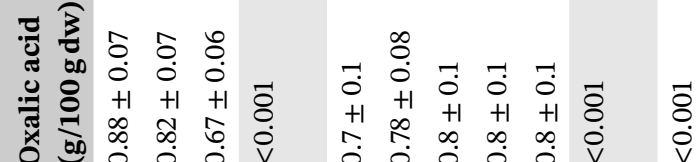

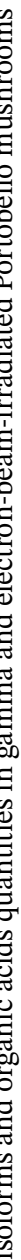

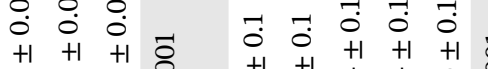

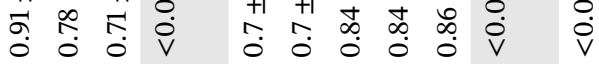

\section{邹}

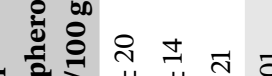

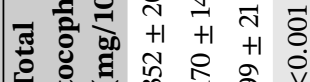

$\stackrel{\ominus}{ } \stackrel{ }{ } ㅋ$

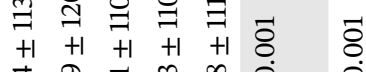

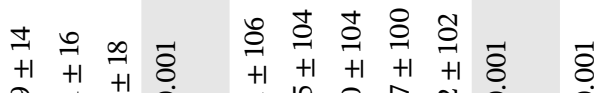

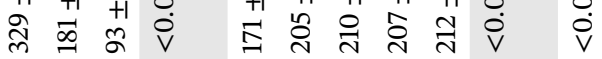

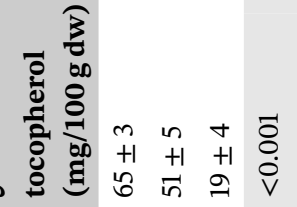

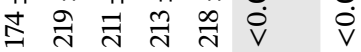

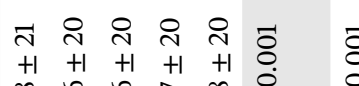

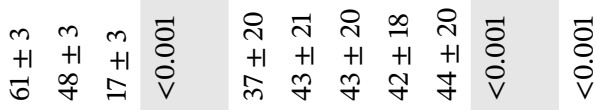

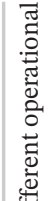

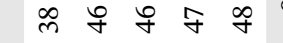

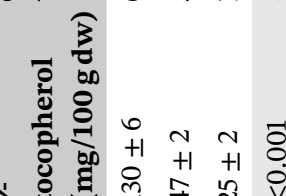

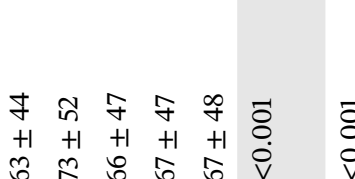

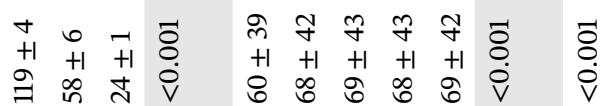

$\pi+\frac{\pi}{+1} \overline{8}$

일

f 아

\begin{tabular}{ll} 
& \\
\hline & $\overrightarrow{8}$ \\
$\dot{8}$ & $\dot{0}$
\end{tabular}

䒕

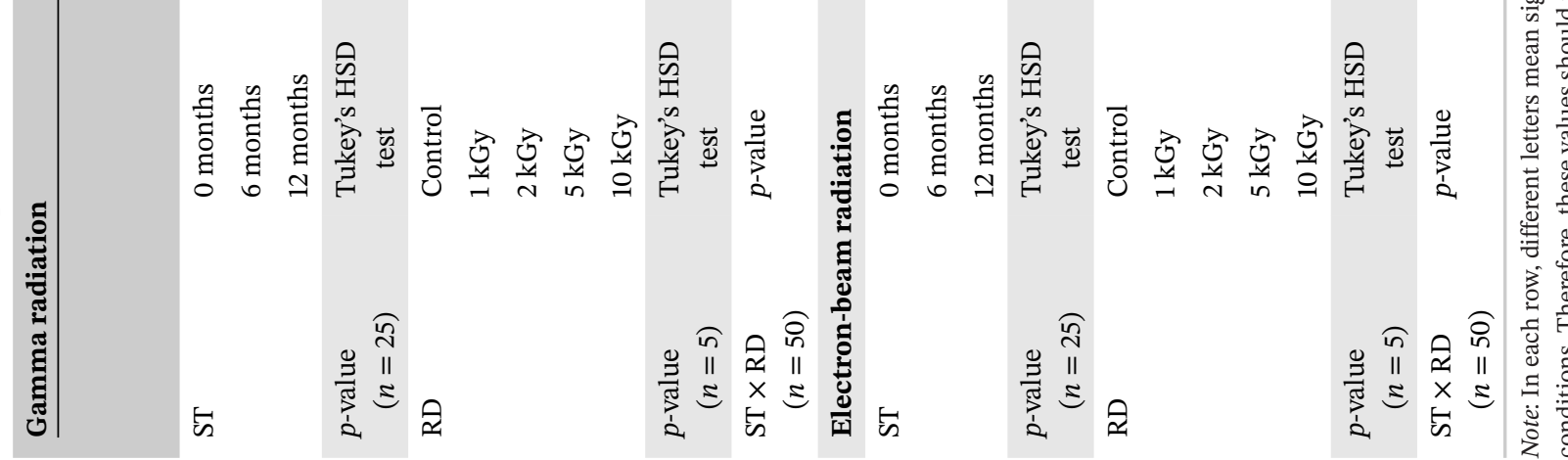

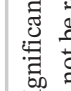




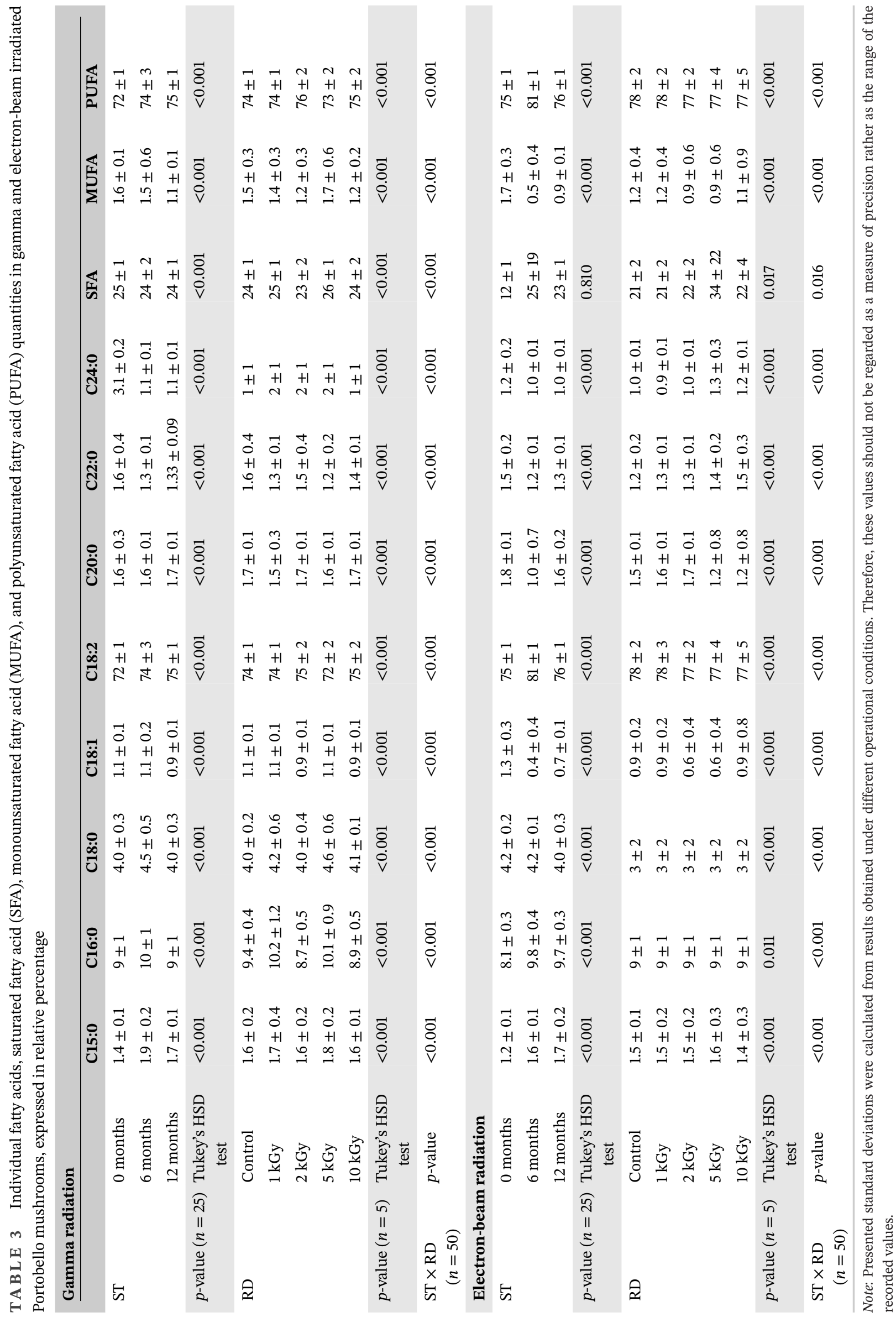


F I G U RE 1 Estimated marginal means (EMM) plots of (a) fat (gamma radiation), (b) proteins (electron-beam radiation), and (c) total sugars (gamma radiation) (a)

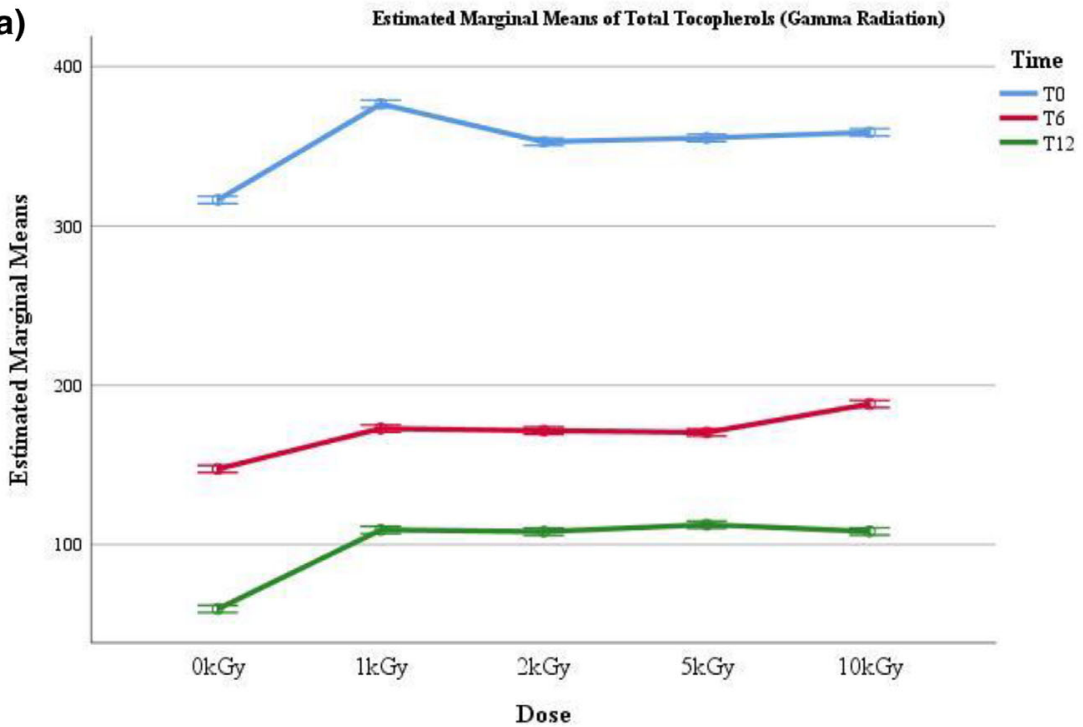

(b)

Estimated Marginal Means of Total Tocopherols (E-Beam Radiation)

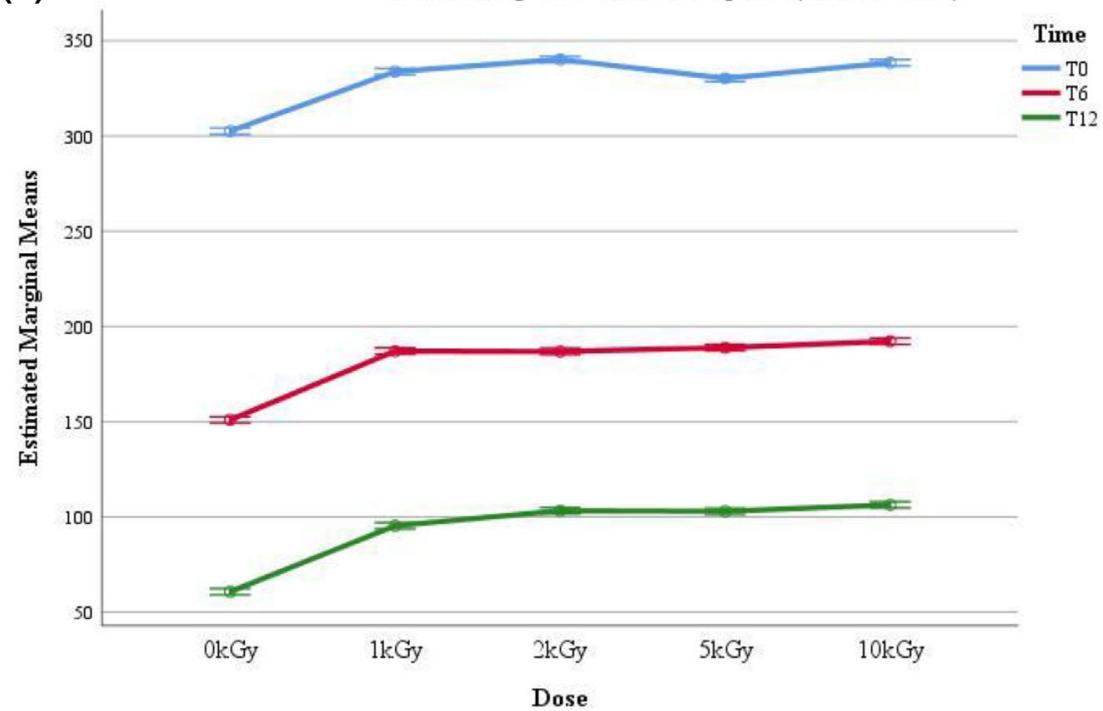

(c)

Estimated Marginal Means of Oxalic Acid (Gamma Radiation)

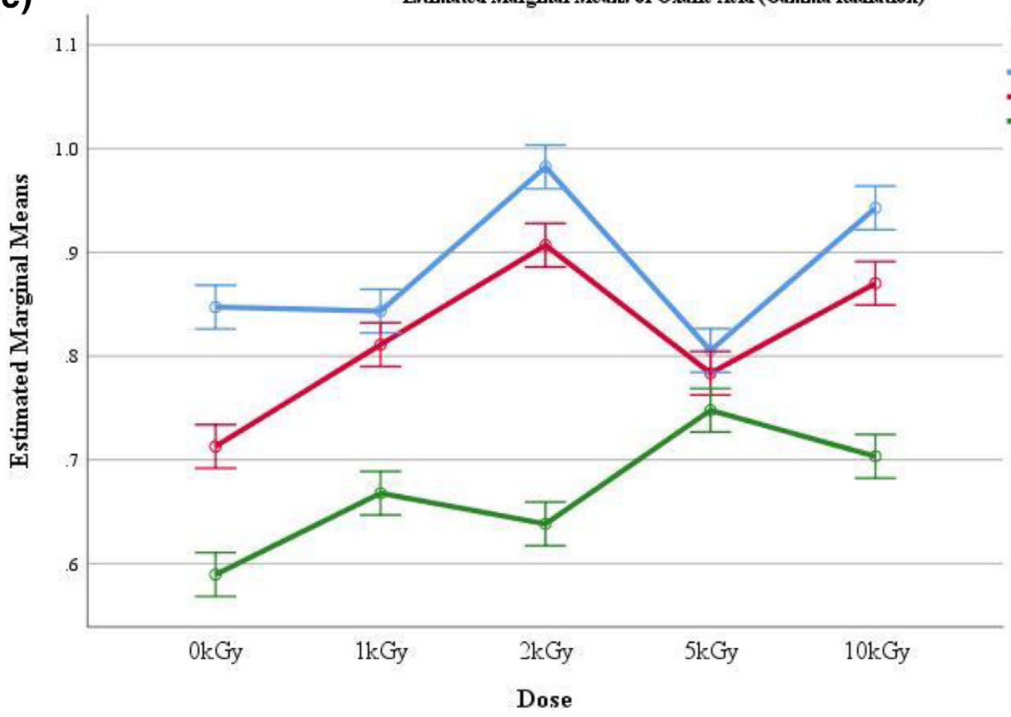


(a)

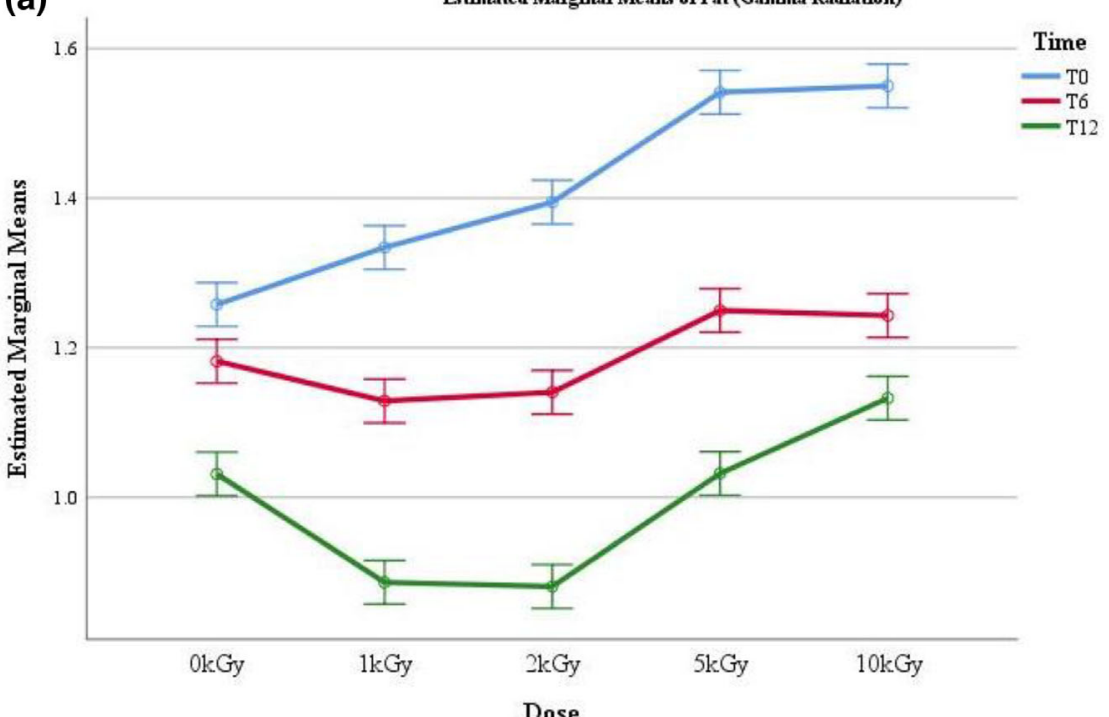

(b)

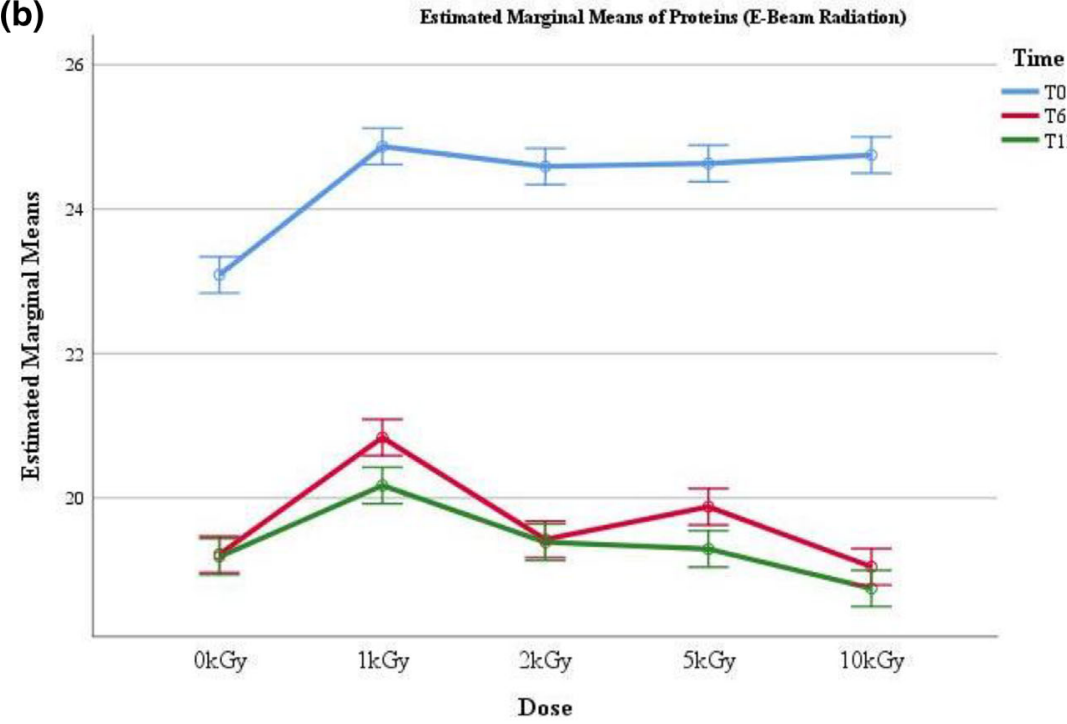

(c)

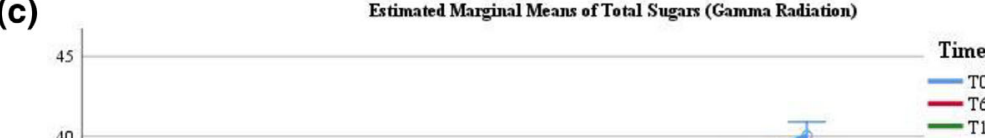

F I G U R E 2 EMM plots of (a) total tocopherols (gamma radiation), (b) total tocopherols (electron-beam radiation), and (c) oxalic acid (gamma radiation)

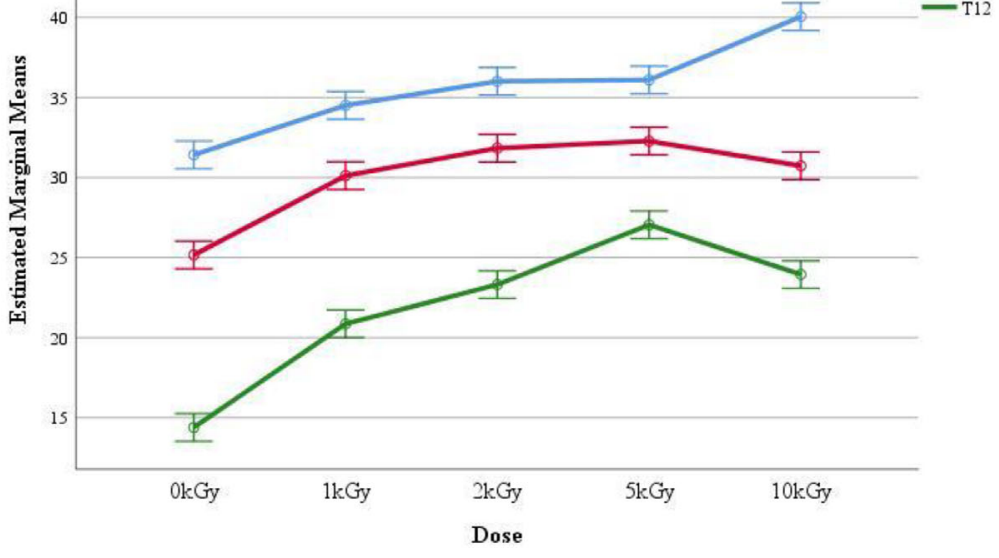


showed a higher impact than RD. All RDs showed preserving capabilities with an increase of about $50 \mathrm{mg} / 100 \mathrm{~g}$ (Figure 2(b)), while ST showed a high impact as seen in the gap between non-stored samples (blue line) and stored samples (red: 6 months, green: 12 months).

Organic acids are a group of simple organic molecules with acidic properties, present in all living organisms. In the irradiated mushrooms, three organic acids were detected: Oxalic, quinic, and malic acid. Quinic and malic acid were the most abundant, practically in ex aequo, while oxalic acid was not detected over $1 \mathrm{~g} / 100 \mathrm{~g}$. For both radiation processes, a significative interaction was found for all organic acids, and thus general conclusions were sought from the EMM plots. In Figure 2(c), (oxalic acid content in gamma-irradiated Portobello), the effect of ST had a higher influence than RD, although in this case, the dose of $2 \mathrm{kGy}$ seem to have protecting capabilities (for the non-stored samples and 6 months stored ones, while samples stored for 12 months showed a better response at $5 \mathrm{kGy}$ ). This was also verified for quinic acid (results not shown). Regarding electron-beam-irradiated mushroom flours, and in line with the observed for the gamma-irradiated samples, organic acids showed a significative interaction in all cases. Irradiated samples (independently of $\mathrm{RD}$ ) tend to present higher organic acid contents, while a significative decrease was observed over ST. Independently of $\mathrm{RD}$, electron-beam radiation preserved organic acids in Portobello mushroom flour, while long STs reduce their amounts. These are important effects to take into account for these small molecules due to their relevance in taste, aroma, and overall appreciated properties of mushrooms. Barros et al. (2014) also mentioned that $1 \mathrm{kGy}$ of gamma irradiation was effective to preserve organic acids in Macrolepiota procera mushrooms, pointing out that irradiation could be a complementary preserving technique.

Table 3 shows the individual fatty acids found in both mushrooms, as well as the groups of saturated fatty acid (SFA), monounsaturated fatty acid (MUFA) and polyunsaturated fatty acid (PUFA), expressed in relative percentage. Only the eight most abundant individual fatty acids are shown, from a total of 16 identified. In both cases, C18:2 was the most abundant fatty acid with a range of $72 \%$ to $81 \%$, followed by C16:0. Overall, PUFA showed the highest amounts, also ranging from $81 \%$ to $82 \%$, while SFA only registered a percentage of $12 \%$ to $34 \%$, and MUFA being the lowest group, under $2 \%$. This high incidence of PUFA shows the health beneficial unsaturated fat found in mushroom flour, which also helps their acceptance as healthy foods. Regarding the individual fatty acids, all samples showed a significant interaction between ST and RD, meaning that even though there were very low variations in the fatty acids, both ST and RD had an influence on the results. No tendencies could be extracted from the EMM plots, thus, concluding that due to the very low moisture, lipid peroxidation was very low, and the influence of the ST would not be drastic. Concomitantly, the influence of the different RDs did not have a great effect on the individual fatty acids.

\section{4 | CONCLUSION}

The main objective of this work was to assess the effect of different RDs on the chemical parameters of Portobello mushrooms flour (a sub-product of the fresh mushroom industry) stored at different intervals, as well as the difference between radiation sources, gamma rays, and electron beam. In this work it was possible to validate the use of both technologies with minimal effects on its main characteristics, allowing its preservation for longer times (up to 12 months) making it available to the food industry, allowing it to be incorporated into other foods, without compromising its main nutritional characteristics. Ionizing radiation using electron beam or gamma rays (up to a dose of $10 \mathrm{kGy}$ ) did not induce severe changes in the tested parameters, and the slight changes are all benefiting the preservation of specific nutrients like sugars and fat but also tocopherols or organic acids.

\section{ACKNOWLEDGMENTS}

The authors are grateful to the Foundation for Science and Technology (FCT, Portugal) for financial support through national funds FCT/MCTES to CIMO (UIDB/AGR/00690/2020), C2TN (UID/Multi/04349/2013) for R.V.C. Cardoso's grant (SFRH/BD/137436/2018), M. Carocho's research contract. L. Barros and A. Fernandes also thank FCT's funding through the institutional scientific employment program-contracts. This work is funded by the European Structural and Investment Funds (FEEI) through the Regional Operational Program North 2020, within the scope of Project Mobilizador ValorNatural ${ }^{\circledR}$. Acknowledgments are also due European Agricultural Fund for Rural Development (EAFRD), through the Rural Development Program (PDR2020), within the scope of Project MicoCoating (PDR2020-101-031472).

\section{AUTHOR CONTRIBUTIONS}

Formal analysis, writing-original draft: Rossana V. C. Cardoso. Data curation, writing-review and editing: Marcio Carocho. Investigation: Ângela Fernandes. Data curation: João C. M. Barreira. Supervision: Sandra Cabo Verde. Investigation: Pedro M. P. Santos. Investigation, writingreview and editing: Amilcar L. Antonio. Supervision: Ana M. Gonzaléz-Paramás. Funding acquisition, project 
administration, supervision: Lillian Barros. Funding acquisition: Isabel C. F. R. Ferreira.

\section{CONFLICT OF INTEREST}

The authors state no conflict of interest.

\section{OR C ID}

\section{Marcio Carocho (1) https://orcid.org/0000-0002-8978-4547}

\section{RE F E RE N C ES}

Akram, K., Ahn, J. J., Shahbaz, H. M., Jo, D., \& Kwon, J. H. (2013). Effectiveness of thermoluminescence analysis to detect low quantity of gamma-irradiated component in non-irradiated mushroom powders. Journal of Luminescence, 136, 395-400.

Antonio, A. L., Cabo Verde, S. C., \& Ferreira, I. C. F. R. (2018). Introduction. in "food irradiation technologies-Concepts applications and outcomes. Royal Society of Chemistry.

AOAC. (2016). Official methods of analysis of AOAC international (20th ed.). AOAC International.

Barreira, J. C. M., Oliveira, M. B. P. P., \& Ferreira, I. C. F. R. (2014), Development of a novel methodology for the analysis of ergosterol in mushrooms. Food Analytical Methods, 7, 217-223.

Barros, L., Pereira, C., \& Ferreira, I. C. F. R. (2013a). Optimized analysis of organic acids in edible mushrooms from portugal by ultra fast liquid chromatography and photodiode array detection. Food Analytical Methods, 6, 309-316.

Barros, L., Pereira, E., Calhelha, R. C., Dueñas, M., Carvalho, A. M., Santos-Buelga, C., \& Ferreira, I. C. F. R. (2013b). Bioactivity and chemical characterization in hydrophilic and lipophilic compounds of Chenopodium ambrosioides L. Journal of Functional Foods, 5, 1732-1740.

Bernaś, E. (2018). Comparison of the mechanism of enzymatic browning in frozen white and brown $A$. bisporus. European Food Research and Technology, 244, 1239-1248.

Cardoso, R. V. C., Fernandes, Â., Barreira, J. C. M., Cabo Verde, S., Antonio, A. L., Gonzaléz-paramás, A. M., Barros, L., \& Ferreira, I. C. F. R. (2019). Effectiveness of gamma and electron beam irradiation as preserving technologies of fresh Agaricus bisporus Portobello: A comparative study. Food Chemistry, 278, 760-766.

Cardoso, R. V. C., Carocho, M., Fernandes, A., Zied, D. C., Cobos, J. D. V., González-Paramás, A. M., Ferreira, I. C. F. R., \& Barros, L. (2020). Influence of clacium silicate on the chemical properties of Pleurotus ostreatus var. florida (Jacq.) P. Kumm. Journal of Fungi, 6(4), 299.

Djekic, I., Vunduk, J., Tomašević, I., Kozarski, M., Petrovic, P., Niksic, M., Pudja, P., \& Klaus, A. (2017). Application of quality function deployment on shelf-life analysis of Agaricus bisporus Portobello. LWT-Food Science and Technology, 78, 82-89.

Fernandes, Â., Antonio, A. L., Barreira, J. C. M., Botelho, M. L., Oliveira, M. B. P. P., Martins, A., \& Ferreira, I. C. F. R. (2013a). effects of gamma irradiation on the chemical composition and antioxidant activity of Lactarius deliciosus L. wild edible mushroom. Food and Bioprocess Technology, 6, 2895-2903.

Fernandes, Â., Barreira, J. C. M., Antonio, A. L., Oliveira, M. B. P. P., Martins, A., \& Ferreira, I. C. F. R. (2014a). Combined effects of electron-beam irradiation and storage time on the chemical and antioxidant parameters of wild Macrolepiota procera dried samples. Food and Bioprocess Technology, 7, 1606-1617.
Fernandes, Â., Barreira, J. C. M., Antonio, A. L., Oliveira, M. B. P. P., Martins, A., \& Ferreira, I. C. F. R. (2014b). Feasibility of electronbeam irradiation to preserve wild dried mushrooms: Effects on chemical composition and antioxidant activity. Innovative Food Science and Emerging Technologies, 22, 158-166.

Fernandes, Â., Barreira, J. C. M., Antonio, A. L., Oliveira, M. B. P. P., Martins, A., \& Ferreira, I. C. F. R. (2014c). Effects of gamma irradiation on chemical composition and antioxidant potential of processed samples of the wild mushroom Macrolepiota procera. Food Chemistry, 149, 91-98.

Fernandes, Â., Barreira, J. C. M., Antonio, A. L., Oliveira, M. B. P. P., Martins, A., \& Ferreira, I. C. F. R. (2016). Extended use of gamma irradiation in wild mushrooms conservation: Validation of $2 \mathrm{kGy}$ dose to preserve their chemical characteristics. $L W T$-Food Science and Technology, 67, 99-105.

Fernandes, Â., Barreira, J. C. M., Antonio, A. L., Rafalski, A., Oliveira, M. B. P. P., Martins, A., \& Ferreira, I. C. F. R. (2015). How does electron beam irradiation dose affect the chemical and antioxidant profiles of wild dried Amanita mushrooms? Food Chemistry, 182, 309-315.

Fernandes, Â., Barreira, J. C. M., Antonio, A. L., Santos, P. M. P., Martins, A., Oliveira, M. B. P. P., \& Ferreira, I. C. F. R. (2013b). Study of chemical changes and antioxidant activity variation induced by gamma-irradiation on wild mushrooms: Comparative study through principal component analysis. Food Research International, 54, 18-25.

Fernandes, Â., Barreira, J. C. M., Günaydi, T., Alkan, H., Antonio, A. L., Oliveira, M. B. P. P., Martins, A., \& Ferreira, I. C. F. R. (2017). Effect of gamma irradiation and extended storage on selected chemical constituents and antioxidant activities of sliced mushroom. Food Control, 72, 328-337.

Fernandes, Â., Barros, L., Antonio, A. L., Barreira, J. C. M., Oliveira, M. B. P. P., Martins, A., \& Ferreira, I. C. F. R. (2014d). Using gamma irradiation to attenuate the effects caused by drying or freezing in Macrolepiota procera organic acids and phenolic compounds. Food and Bioprocess Technology, 7, 3012-3021.

Ferreira, I. C. F. R., Antonio, A. L., \& Cabo Verde, S. (2018). Food irradiation technologies: Concepts, applications and outcomes. Royal Society of Chemistry.

Guan, W., Zhang, J., Yan, R., Shao, S., Zhou, T., Lei, J., \& Wang, Z. (2016). Effects of UV-C treatment and cold storage on ergosterol and Vitamin D2contents in different parts of white and brown mushroom (Agaricus bisporus). Food Chemistry, 210, 129-134.

Heleno, S. A., Barros, L., Sousa, M. J., Martins, A., \& Ferreira, I. C. F. R. (2009). Study and characterization of selected nutrients in wild mushrooms from Portugal by gas chromatography and high performance liquid chromatography. Microchemical Journal, 93, 195-199.

Khan, Q. U., Mohammadzai, I., Shah, Z., Ullah, I., Khattak, T. N., Noreen, H., \& Hassan, W. (2018). Effect of gamma irradiation on nutrients and shelf life of peach (Prunus persical) stored at ambient temperature. The Open Conference Proceedings Journal, 09, 8-15.

Kic, P. (2018). Mushroom drying characteristics and changes of colour. Engineering for Rural Development, 17, 432-438.

Pereira, E., Antonio, A. L., Barreira, J. C. M., Barros, L., Bento, A., \& Ferreira, I. C. F. R. (2015). Gamma irradiation as a practical alternative to preserve the chemical and bioactive wholesomeness of widely used aromatic plants. Food Research International, 67, 338348 . 
PR Newswire. (2018). Global mushroom market 2018-2026: The market is expected to grow at a CAGR of $7.9 \%$. https://www.prnewswire.com/news-releases/global-mushroommarket-2018-2026-the-market-is-expected-to-grow-at-a-cagr-of7-9-300712332.html

Reis, F. S., Barros, L., Martins, A., \& Ferreira, I. C. F. R. (2012). Chemical composition and nutritional value of the most widely appreciated cultivated mushrooms: An inter-species comparative study. Food and Chemical Toxicology, 50, 191-197.

Taofiq, O., Fernandes, Â., Barros, L., Barreiro, M. F., \& Ferreira, I. C. F. R. (2017). UV-irradiated mushrooms as a source of vitamin D2: A review. Trends in Food Science and Technology, 70, 82-94.

Teichmann, A., Dutta, P. C., Staffas, A., \& Jägerstad, M. (2007). Sterol and vitamin D2 concentrations in cultivated and wild grown mushrooms: Effects of UV irradiation. LWT-Food Science and Technology, 40, 815-822.

Wang, J., Li, W., Li, Z., Wu, W., \& Tang, X. (2018). Analysis and evaluation of the characteristic taste components in portobello mushroom. Journal of Food Science, 83, 1542-1551.
Zhang, K., Pu, Y. Y., \& Sun, D. W. (2018). Recent advances in quality preservation of postharvest mushrooms (Agaricus bisporus): A review. Trends in Food Science and Technology, 78, 72-82.

How to cite this article: Cardoso, R.V.C., Carocho, M., Fernandes, A., Barreira, J.C.M., Cabo Verde, S., Santos, P.M.P., Antonio, A.L., Gonzalez-Paramas, A.M., Barros, L., \& Ferreira, I.C.F.R. Combined effects of irradiation and storage time on the nutritional and chemical parameters of dried Agaricus bisporus Portobello mushroom flour. J Food Sci. 2021;86:2276-2287. https://doi.org/10.1111/1750-3841.15755 


\section{Meet the Microbes: The Role of Microorganisms in the Safety, Quality, and Shelf life of Meat and Meat Products}

\section{Free Virtual Seminar | December 2, 2021 | 12PM EST}

Microorganisms in meat play a significant role in the safety, quality, and shelf life of meat and meat products. Pathogenic organisms such as Salmonella, E.coli 0157:H7, Campylobacter, and Listeria monocytogenes represent important food safety hazards and public health threats. Other microorganisms are involved in spoilage, quality issues, and reduced shelf life.

In this webinar, we will explore major pathogens in meat and the public health burden of foodborne illness outbreaks involving these pathogens, issues dealing with sampling and the microbiological testing of meat, and industry and regulatory approaches for assuring the safety and quality of meat and meat products. We will also discuss the 25th anniversary of HACCP regulation for meat and meat products, and its impact on meat safety.

\section{Register here}

\section{Food Safety}

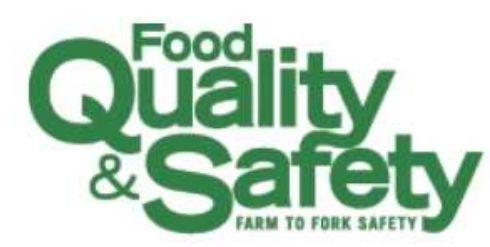

